\title{
التصوف وسيكولوجية الحضور المتسامي بين الدافع والغاية
}

\section{دراسة استكثافية}

وليد منير

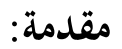

يعد التصوف من أبرز الظواهر الروحية في تاريخ الإسلام. ويرجع البعض به إلى عدد من كبار الصحابة والتابعين بعد النبي صلى الله عليه وسلم نفسه. ولعل أشهر هؤلاء هم: على بن أبي طالب وسلمان الفارسي وأبو ذر الغفاري، وحارثة الأنصاري، ولفيف من أهل الصُّفّة الذين كانوا يمثلون فقراء المسلمين، ثم الجيل التالي من دعاة الزهد والعزلة والتقوى مثل أويس القرين، وزين العابدين علي بن الحسين بن علي المعروف بالسجاد، والحسن البصري وغيرهم. ويقال أن مصطلح "التصوف" قد أتى من معنى الصفاء أو لباس الصوف. ولباس الصوف علامة من علامات الفقر التي كان يعرف بها متواضعو الحال قديماً. ومازال الصوفية حتى يومنا هذا يسمون أنفسهم الفقراء، ولكن العلامة انتقلت في الحقيقة منذ وقت مبكر من دائرة الشكل إلى دائرة المضمون، فغدت تدل، قبل كل شيء، "على الفقر إلى الله تعالى" بوصفه مناط إخلاص توجه القلب إلى الحق سبحانه، وهو المعنى الذي يدور عليه التصوف مفهوماً وسلوكاً في غير حاله.

تتحدد أهمية موضوع التصوف من الزاوية النفسية، في كونه تحربه ذاتية داخلية تقوم، في جوهرها، على موقف وجودي مفاده أن الإنسان غريب عن كل ما سوى الله، وأنه يحتاج كي يستعيد انتماءه الأصلي إلى مجاوزة كل العلائق بوصفها عوارض تحول بينه وبين اتصاله المنشود بروح المطلق وأن الفاعلية الحقيقية للوجود تنبع من إدراك خلوه من كل حقيقة إلا تجليه فيه تعالى بمظاهره كافة.

ولابد أن استعداد الاستجابة للمثيرات التي قد تبرهن على هذا الطرح الخاص، أو تصب في معناه ينهض على حالة عقلية- نفسية خاصة تتيح للانا الصوفية أن تسترسل في اتجاه الصعود من الكثرة إلى الواحد، ولابد أن الحساسية المتفردة التي تطبع الحياة والكون بهذه الرؤية ترفد من روافد عميقة تصل المعرفة * مدرس الأدب العربي بكلية التربية النوعية بجامعة القاهرة. دكتوره في النقد الأدبي الحديث 
الماورائية أو المعرفة الكشفية بما يسمونه "عين البصيرة". وهذا الاستبصار الباطني عملية تنطوي دون شك على أسرار كثيرة، ولكنها تقع ظاهريا في نقطة التقاطع بين الرؤية والرؤيا. هذه النقطة، ربما، هي مثال التناول النفسي لأبعاد شخصية الرائي باعتبار كونه مندبجاً، برغم تناهيه، في انخطافه نخو اللامتناهي.

ودراستنا دراسة استكشافية تحدف إلى معرفة سيكولوجية "العلو" أو الحضور المتسامي بين الدافع والغاية. وهي تأخذ، من أجل ذلك، بطرف من علم النفس الفلسفي، وبطرف أخر من علم النفس ر-ن الانعكاسي، وتدخل إجراءاها في المجال الاستباطي للمعرفة الذوقية متبنية نوعاً من الدفاع عن هذه المعرفة بوصفها وثبة حدسية إلى ما وراء الحس.

وظني أن هذا المنهج يضمن قدراً من الموضوعية التي توجه نزوع الانحياز وتحمه وتقوم مساره دون أن تمحوه أو تستبعده تماماً، فالحياد حتى في العلوم الطبيعية كالفيزياء والكيمياء والبيولوجيا وغيرها وَهْم مثالي كما أكد كثير من العلماء والفلاسفة. إننا لا نولد كما يقول "جيتون" ونخن ننتمي إلى العالم بل إلى شيء نبنيه داخل العالم. ومن ثم فنحن غير محايدين بالضرورة نظراً لطبيعة اختياراتنا. وانحيازي لفكرة التصوف قد يكون اختياراً ولكنه اختيار لا يمنعني بحال من مباشرة الفهم والتأمل والتحليل كي أخلص من كل ذلك إلى نتائج قد أتوقعها وقد لا أتوقعها.

إن انفتاحنا على الفكرة هو الذي يبين أهميتها، ويحدد الهدف من سبر أغوارها، وهو عمل من صميم أعمال العقل بقدر ما هو من صميم أعمال العاطفة، وقد ورد في الأثر: "أن أول ما خلق الله العقل ثم بن خاطبه فقال ما خلقت خلقاً أكرم علي منك"، وجاء فيه أيضاً أن الله تعالى قال: "ما وسعتني أرضي ولا سمائي وإنما وسعني قلب عبدي المؤمن"، والموازنة تدل على استواء المرتبتين، وتساوى المنزلتين فإذا كان القلب، حسب معناه اللامادي الذي ورد بالقرآن هو اللطيفة الربانية التي أودعها تعالى كما يقول العارفون في صدر الإنسان فليس علينا أن ننفر من تغلغل أثر القلب في العقل خاصة أن هذا التغلغل واقع لا مناص منه ولا فكاك مهما حاول التفكير المنهجي الواعي أن يتجنبه. لذلك فقد كان ابن عطاء الله السكندري بصيراً في حكمته التي تقول: "الفكرة سراج القلب فإذا انطفأت فلا سراج له. 
قال معروف الكرخي رحمه الله: "التصوف هو الأخذ بالحقائق، واليأس مما في أيدي الحلائق". وقال الإمام الجنيد: "التصوف ذكر مع اجتماع، ووجد مع استماع، وعمل مع اتباع". وقال الشبلي: "التصوف الجلوس مع الله تعالى بلا هم." وقال أبو يعقوب المزابلي: "التصوف حال تضمحل فيها معالم الإنسانية." وقال أبو سهل الصعلوكي: "التصوف الإعراض عن الاعتراض."

نستطيع أن نخلص من كل ما سبق إلى أن البعد النفسي في مفهوم التصوف عند الصوفية المسلمين يدور على معنى "الاستحواذ الشعوري." ونحن نعني بالاستحواذ الشعوري اصطلاحاً، امتلاك موضوع أو شخص لكامل الشعور بصورة تستدعى التركيز الكامل على هذا الموضوع أو ذلك الشخص دون قابلية، ولو جزئية للانفلات من سطوة جاذبية. وهذا يرجع بنا إلى مفهوم الحب في أعلى أشكاله مثالية، حيث يقتضي الإخلاص العاطفي المفرط الفناء الذاتي في المحبوب، وهو ما وشى به قول الحلاج:

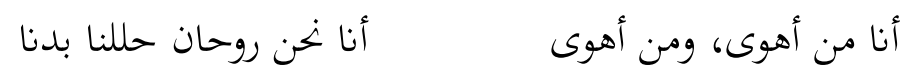

وربما لذلك كان يقدم "سمنون بن حمزة" الحبب على المعرفة، بينما عهد غيره من الصوفية تقديم المعرفة على الحب. بيد أن المعرفة، هنا، فيما يبدو، هي "لوغوس الحب" أو حكمته أو فلسفته، بدليل قول "رويم بن أحمد": المعرفة للعارف مرآة، إذا نظر فيها بتلى له مولاه، وقول محمد بن الفضل الفرأوي: "المعرفة حياة القلب مع الله تعالى"، وقول أبي يزيد البسطامي: "العارف لا يرى في نومه غير الله تعالى، ولا في يقظته غيره، ولا يوافق غيره، ولا يطالع غيره."1

وسوف تقودنا "ابستمولوجيا الحب" إلى دراسة الحساسية العاطفية الخاصة عند الصويف المسلم، فالصوفي- فيما يلوح لي- يطلب نوعاً فريداً من النشوة الوجدانية المتصلة مما لا يتوافر وجوده عند البشر بوصفهم كائنات نسبية تعيش في الزمان المنقطع، وتنحو نهو التناهي. هذا إلى جانب اتصافها بالتقلب والتحول والنسيان والتباس المشاعر والنقصان والأنانية، ومن ثم فهو يبحث عن بغيته في الطرف المقابل، حتى لو كان بجرداً ولا مرئياً، إذا يأنس أن يجد فيه الثبات والصدق والكمال وكرم العطاء.

القشيري، أبو القاسم. الرسالة القشيرية في علم التصوف، تعقيق: معروف زريق، وعلى عبد الحميد، دمشق: دار اخير، 1993م،

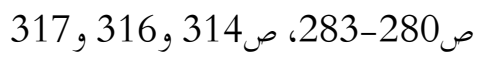


وهو يستبدل بالتمثل الحسي المباشر لله تعالى "حيث لا يجوز عليه ذلك سبحانه" ما يسميه بالتجلي الوجودي للحق وهو التجلي الشهودي الذي يعنى ظهور الحق بصور أسمائه في الأكوان التي هي صورها، 2 وهذا التجلي يستبعه التحقق أي شهود الحق في صور أسمائه التي هي الأكوان. 3 ونلاحظ هنا إننا نعود إلى دائرة المخلوق مرة أخرى ولكن باعتبار كونه صورة لاسم من أسماء الله تعالى: "الجميل، اللطيف، الرحيم، الباسط، النافع، القريب، البديع، الودود.. الخّ" لا باعتباره ماهية في ذاتما. هكذا يستبدل "الاستحواذ الشعوري" امتداده عبر مستوى أخر حيث يجد في العالم التاريخي مادته الملموسة، منتقلاً من المجرد إلى المجسد، ومن اللامرئي إلى المرئي. ولما كان الأمر كذلك صار أعظم ظهور الله تعالى هو بتليه في المرأة للرجل وفي الرجل للمرأة.. فأحب رسول الله صلى الله عليه وسلم النساء لكمال شهود الحق فيهن إذ لا يشاهد الحق مجرداً عن المواد أبداً.. فمن أحب النساء على هذا الحمد فهو حب إلهي ومن أحبهن على جهة الشهوة فهو صورة بلا روح.4 ولعل المعنى نفسه يظهر في قول عبد الوهاب الشعراني: سألت شيخنا علي الخواص: هل الأصل في العالم الذكورة أم الأنوثة؟ فقال: ذكر بعض المحقين أن الأصل فيه الأنوثة ولذلك سرت فيه بأسرها وكانت في النساء أظهر وذلك حببت للأكابر حتى أن موسى عليه السلام أجر نفسه في مهر امرأة عشر سنين. يتحول بذلك الحب البشرى نفسه من نزعة شخصية للاحتواء العاطفي في واقع المرء الجزئي إلى استغراق في صورة الاسم الإلهي ذاته بهدف كمالية شهود الحق من خلال شرط الشهود "عدم التجرد عن المواد" حيث تتدفق النشوة الوجدانية مقترنة بديمومة الوجود الكلي لله الظاهر الباطن. وبهذا المعنى نفهم سيكولوجية الحضور المتسامي للأنا الصوفية في العالم الذي يفتقر بماديته الصرف إلى

القشاني، كمال الدين عبد الرزاق. اصطلاحات الصوفية، تحقيق: محمد كمال جعفر، القاهرة: الميئة المصرية العامة للكاتب، ص 156 3

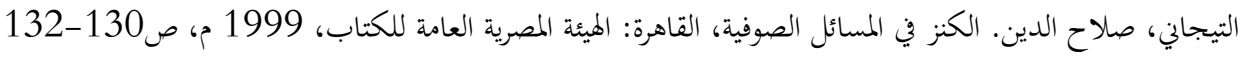
5 
ولأن بعض التجليات الإلهية أعلى من بعض، باعتبار مراتب الظهور: فإنها تتدرج من أصغر ذرة في

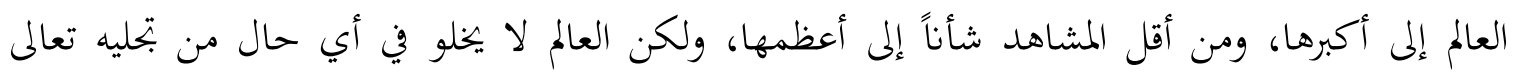
بأسمائه في صور ذلك العالم. ولكل صورة قابلية من قابليات التجلي واستعداده لا تتماثل مع غيرها. وبقدر القابلية تكون نسبة كمال الشهود.

ولا ينبغي الخلط كما يقول المققون بين مذهب بعض الزنادقة في الحلول وبين مذهب التجلي

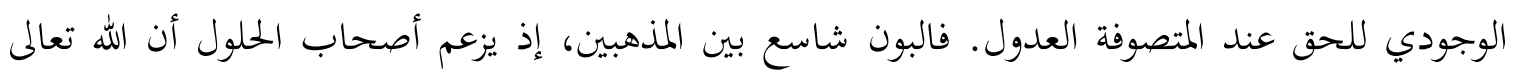
يحل بعين ماهيته في الكائنات والأشياء فتستدجمه ويستدجما. والأمر غير ذلك تماماً عند العارفين الواقفين مع الحدود الشرعية، فالله تعالى لا يحل بعين ماهيته في موجود ولكنه يكشف عن صفته في ذلك الموجود، فهو لا يشاهد مجرداً عن المواد بمعنى أنه لا يشاهد إلا باندراج هذا المواد عن صفته بما هي صورة لاسم الصفة.

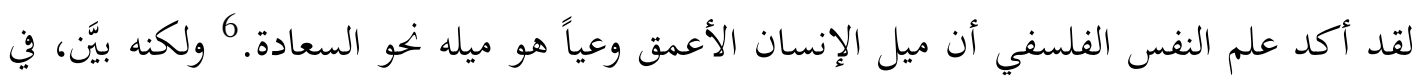
الوقت نفسه، أن هذه السعادة، على المستوى الشعوري، مبهمة وغير محددة رغم ارتباطها بالإرادة. 7 وقد قدم التصوف في بعده النفسي حلاً لهذه المشكلة، لقد حدد السعادة بالتناغم الداخلي الفريد الذي ينبع من الاسترسال مع الله تعالى: "أو المسمى" في بهاء بتحليه عبر صور أسمائه وبذلك تتحق الذات تحققها الأسمى من خلال كوها صورة لاسم له تعالى تطلع على صورة أخرى لاسم له أخر، وتتصل بها على أساس من هذا

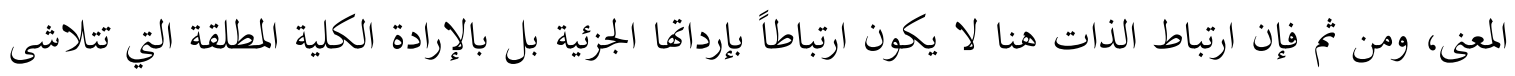
فيها كل إرادة سواها بالضرورة تلاشي الموجة في العباب. وتلد هذه السعادة نوعاً من الوجد واللذة والدهش

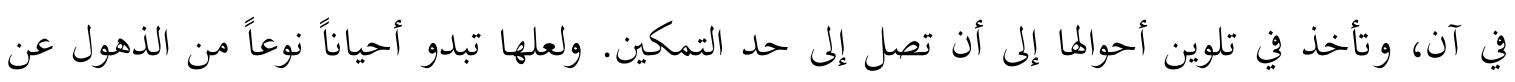
الزمن والمكان. وذلك لأخها تعلو على اللحظة والحيز في تمثلات شواهدها وهو ما تدق عنه العبارة كما

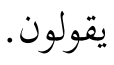

$$
\text { } 6 \text { } 7
$$


يقول "روزهان البقلي" رأيت كأن من العرش إلى الثرى كان بحراً وكان مثل شعاع الشمس ففتح فمي بغير اختيار وأدخل جميعه في فمي فما بقى قطرة إلا شربتها. و ويقول "رأيت ربى مرة بوصف الجمال والجلال ومعه الملائكة وقلت إلهي كيف تقبض روحي؟ فقال أتيك من بطنان الأزل وأقبض روحك بيدي، وأذهب بك إلى مقام العنديه وأسقيك من شراب الدنو، وأظهر لك جمالي وجلالي إلى الأبد كما تريد بلا حجاب." وإذا بتحلى الله تعالى بأسمائه وصفاته جميعاً، فيما عدا اسم الذات العلم في صورة واحدة حصلت -كما يقول الصوفية- الصورة المحمدية؛ فمحمد هو الإنسان الكامل بوصفه النسبة التي بين الله وعبده كما يقول الجيلي رحمه الله. وتفصيل ذلك أن هيئته الصورية الظاهرة الهيكلية أم لصور الكمالات الحسية الوجودية العلوية والسفلية، وهيكليته المعنوية الباطنة التي هي عبارة عن أخلاقه. فهو هيولي المعاني والصور الوجودية، عالم الشهادة فيض ظاهره وعالم الغيب فيض باطنه، وغيب الغيب عبارة عن حقيقته صلى الله عليه وسلم. 10 وهكذا يكون تعلق النفس بصورة النبي صلى الله عليه وسلم تعلقاً بصور الأسماء كافة أي تعلق بتجلي التجليات الإلهية بجتمعه في مظاهر الوجود المخلوق.

ومن الأسرار النفسية النفيسة عند الصوفية المسلمين تقسيم بعضهم للأسماء الإلهية بحسب ملاءمتها لصور النفس المنوطة هما في طريق الترقي السلوكي نحو الحق تعالى. وهذه الأسماء سبعة يطلقون عليها الأسماء الأصول: "لا اله إلا الله" للنفس الأمارة ومحلها الصدر، و"الله" للنفس اللوامة ومحلها القلب، و"هو" للنفس تلى المسماة بالملهمة ومحلها الروح، و"حيّ" للنفس المطمئنة ومحلها السر، و"واحد" للنفس الرضية ومحلها سر السر، و"عزيز" للنفس المرضية ومحلها الحنفاء، و"ودود" للنفس الكاملة ومحلها الخفية. 11 ويعرف الصوفية المسلمون كثيراً من دقائق الآليات النفسية التي يسدون بها ثغرات الخلل المتمل في نية الحضور الداخلي المتصل مع الله تعالى مما يضمن لم تحصيل ثثرات الذكر الناضجة حيث إن الذكر كما يقول محمد الواسطي،

$$
\begin{aligned}
& 8 \\
& 9
\end{aligned}
$$

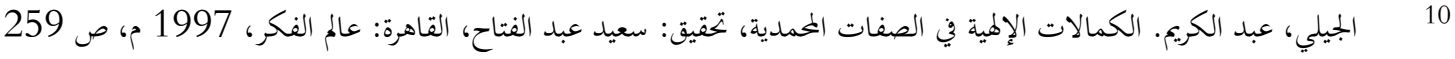

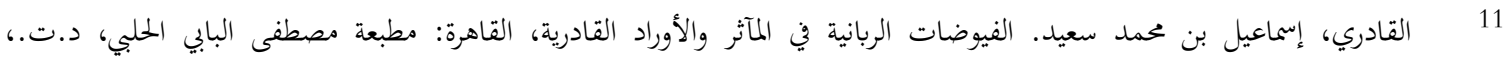


خروج من ميدان الغفلة إلى فضاء المشاهدة. والمشاهدة هي حضور الحق من غير بقاء قمة بتوالي أنوار التجلي على قلب العبد دون أن يتخلله ستر أو انقطاع. 12

ومن دقائق الآليات النفسية الحميمة التي تتوارثها طائفة من الصوفية ضَبْطُ النَفَس (بفتح الفاء) والحركة، على نهو معين، مع النطق المتكرر باسم من أسمائه تعالى، كأن يجلس الذاكر مفترشاً كما في الصلاة، ويضع يديه على فخذيه، ويخفض رأسه إلى أن يقرب إلى الفخذين، ثم يجذب من تحت السرة (هو) بالصوت الظاهر مع قبض النفس إلى أن يصل إلى الدماغ، ويقف عنده لمحه ثم يستأنف. 13 وقريب من ذلك ما سمُوّهو "بذكر العنقاء." وطريقه أن يجلس الذاكر على الركبتين ويداه على فخذيه ثم أن يضرب على الثدي الأيسر قائلاً (يا)، ويجر النَفَس "بفتح الفاء" من السرة متصلاً قائلاً (هو) إلى فوق، ثم يضرب على الثدي الأيمن ويجر كذلك، ويشتغل به متعاقباً متوالياً فإذا واظب عليه يظهر له ذكر عنقاء أسماء الله تعالى.14 ويبدو أن عنقاء أسماء الله تعالى دلالة على حياة النفس الحقيقية بالله بعد موتا بذاتما رغم حضورها الظاهر في الحياة. ولعل هذا معنى قول الجنيد رحمه الله حين سئل عن التصوف: هو أن يميتك الحق عنك ويجييك به.

ومن المهم أن نذكر أن المعرفة الصوفية تتصل في كثير من محاورها بعدد من المصطلحات النفسية البادهة مثل: القبض، والبسط، الأنس، والوجد، والخاطر، والوارد، والرضا، والمراقبة... الخ.

وتشير هذه المصطلحات في جملتها إلى أحوال واستعدادات ومزاجات وملكات وانفعالات واستجابات نفسية نختلفة، وتمدف إلى تحديد المظاهر الواعية واللاواعية للتجربة الميتافيزيقية الشخصية. التصوف إذن في بعده النفسي استبطان عميق لحقيقة التوافق الأصيل بين الحضور الإلهي في الوجود الشخصي للإنسان وقابلية هذا الإنسان للانكشاف عن إمكاناته العليا عبر ذلك الحضور بما يحقق له معناه الجوهري المفقود.

$$
\begin{aligned}
& 12
\end{aligned}
$$

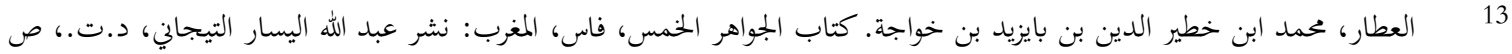

$$
\begin{aligned}
& 366 \\
& 14
\end{aligned}
$$




\section{تأصيل البعد النفسي في مفهوم التصوف من واقع الكتاب والسنة:}

نستطيع، إذا أمعنا النظر، أن نعثر في كتاب الله تعالى وسنة رسوله صلى الله عليه وسلم على جذور عميقة لمفهوم التصوف في بعده النفسي مما يدل على أن أطروحات التصوف الإسلامي لا تستعير أشكالها ومضموناتا الأساسية، بدءاً، من مصادر دينية وثقافية أخرى كما يروج البعض، وان كانت لا بتح غضاضة في الإفادة منها باعتبارها تراثاً إيمانياً روحياً له فاعليته المؤثرة.

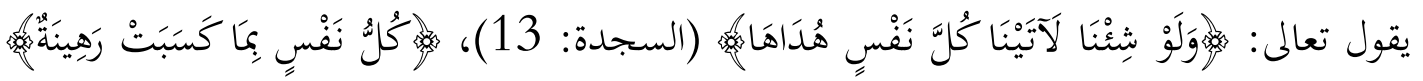

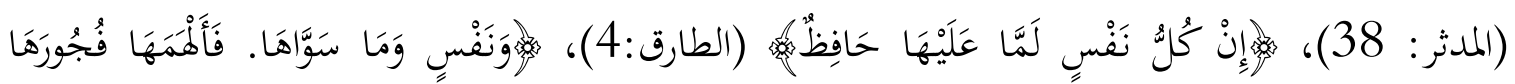

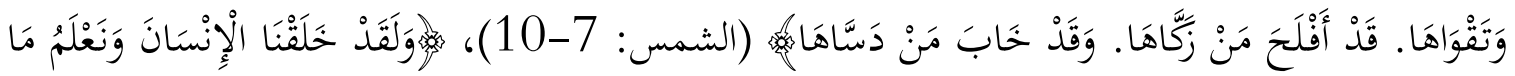

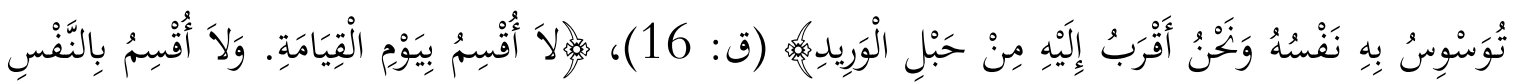

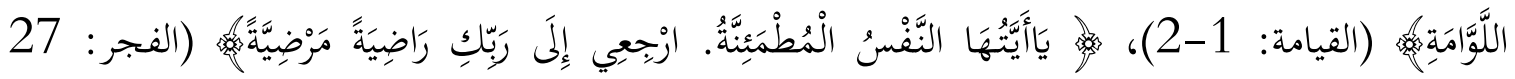

من هذه الآيات وغيرها استخلص الصوفية بجموعة من المبادئ النفسية المهمة كان أبرزها: المراقبة، التزكية، الاطمئنان إلى حكم الله تعالى، قمع الموى، الصبر، والاسترسال مع مقتضى العبودية. وتأكدت هذه المبادئ النفسية بما جاء به الحديث النبوي الشريف من موافقة تدعم معنى الآيات القرآنية، وتوضحها، وتضرب على وترها، إضافة إلى مسلك الرسول صلى الله عليه وسلم نفسه، ومنهاجه في النظر والفعل مما يوسع من مدى الأيمان بما هو توجه داخلي. قال صلى الله عليه وسلم: "أفضل الجهاد أن يجاهد الرجل نفسه وهواه." (رواه ابن النجار عن أبي ذر). وقال: "عليكم بالحزن فانه مفتاح القلب." (رواه الطبراني عن ابن عباس). وقال: "عليكم بالسكينة." (رواه البيهقي عن أبي موسى). وقال: "قد أفلح من أخلص قلبه للأيمان، وجعل قلبه سليماً، ولسانه صادقاً، ونفسه مطمئنة، وخلقته مستقيمة، وأذنه مستمعة، وعينه ناظره" (رواه

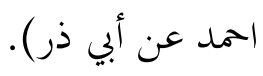

وقال: "قل اللهم أنى أسالك نفساً مطمئنة، تؤمن بلقائك، وتقنع بعطائك".(رواه الطبراني عن أبي أمامة). وقال: "لو تعلمون من الدنيا ما أعلم لاستراحت أنفسكم منها" (رواه البيهقي عن عروة). وقال: 
"إنما العمى من تعمى بصيرته" (رواه البيهقي عن عبد الله بن جراد). وقال: "من رضي عن الله تعالى رضي

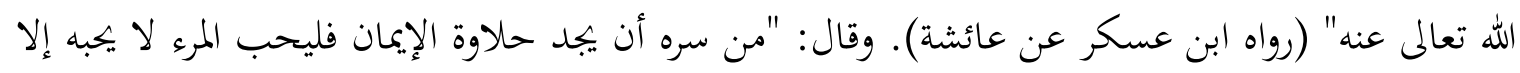

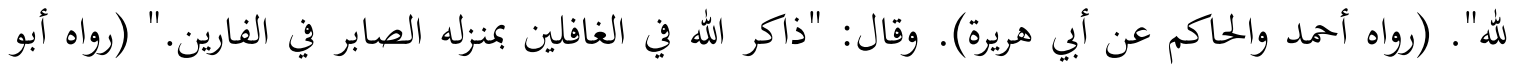

$$
\text { نعيم عن أبي الدرداء). (رواه. }
$$

ومن الواضح، هنا أن الزهد والخشوع والصدق والرضا والطمأنينة والغبطة وجوه متعددة لتوطين النغس

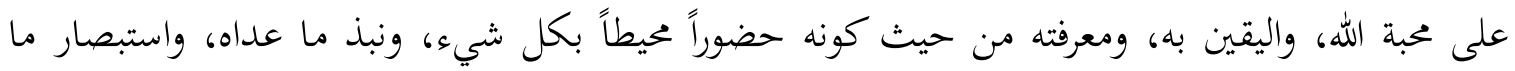

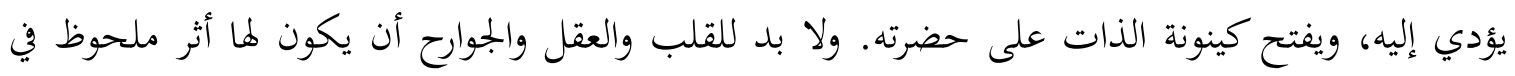
ربط النفس بأفقها الأسمى ما دامت التجربة النفسية، في بجموع معطياتا، ليست مغصولة، باعتبار زمنية ججراها، عن العناصر التكوينية الأخرى للإنسان، بيد أن الناظم الرئيسي في هذا الربط يخضع لمنظور الحقيقة النفسية ذاتا، ويدور في فلكها، وينهل من حيوية فروضها، ويوجه سائر الامكانات والمناشط كي تصب في تلفي غائيتها. وقد لا يتحقق ذلك كله، فيما نرى، إلا بتوفر استعداد أولي مهم معثل إطاراً موحداً لمناحي التجربة: وهذا الاستعداد هو "الوجد"، فالوجد هو الفاعلية الدائرية التي تستمر، في دورتما مرة بعد أخرى، لتضمن توهج التجربة، وألقها، والتماع معدها وبريق تأثيره.

ويروى منصور بن عبد الله أن رجلاً سأل أبا بكر الشبلى: هل تظهر أثار صحة الوجد على

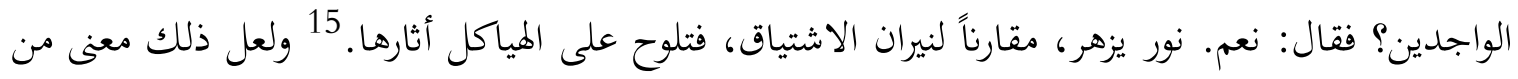

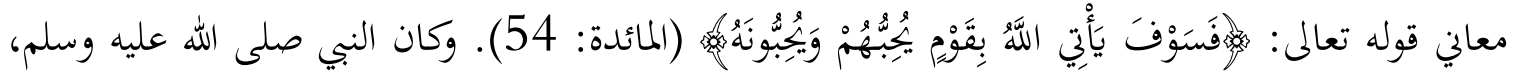

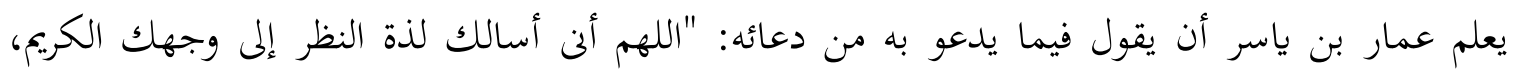
وشوقاً إلى لقائك في غير ضراء مضرة، ولا فنتة مضلة" (رواه النسائي والحاكم عن عمار) .

ومما يظهر من سمات الوجد في مناجاة البي لربه قوله صلى الله عليه وسلم في دعائه: يا صاحب كل

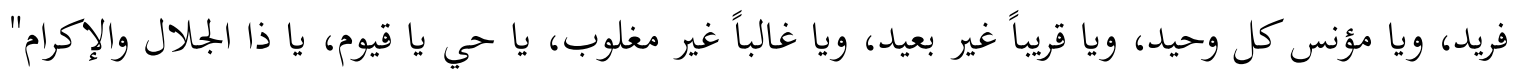

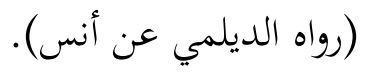

15 
ونهن نعنى بالوجد الذي يمثل إطاراً موحداً لمناحي التجربة شيئاً أكثر اتساعاً في امتداده النفسي المتصل من الانفعال بالسماع أو الوارد أو الفكرة أو الرؤية، كما ترد به الأخبار والحكايات والطرائف المروية عن أهل الطائفة؛ إذ يتأسس الوجد، حسب ما نرى، على قابلية خاصة للاستجابة العاطفية التي تحتوي مظاهر الواقع كافة وما وراءه من مثيرات تحفز الشعور والذاكرة والحدس على استنهاض كوامن الذات وخفاياها في ابتحاه مكاشفات الحق سبحانه بوصفه الواحد الذي تنم عنه الكثرة.

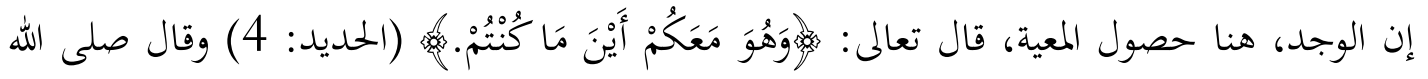
عليه وسلم: "ذر الناس جانباً، واتخذ الله صاحباً". والمعية في الآية الكريمة هي معية الله للعبد، أما المعية في الحديث الشريف فهي معية العبد لله تعالى. والوجد الذي هو حصول المعية، بما يحقق غبطة النفس في ذروة إشرافها على تنوعات التجلي الساري في الأكوان، هو هذا الوجد الذي ينتج عن مجاوزة درجة المعية الأولى إلى درجة المعية الثانية حتى الوصول إلى التحقق بسر الصفات.

ويقول عبد الكريم الجيلي في (منظر المعية) من كتابة (المناظر الآلية): يتجلى الحق تعالى على العبد في

هذا المنظر، فلا يفارق الحق، أعني لا يفارق حضرة شهود التجليات الإلهية، وإلا فما ثمة فراق ولا وصال. 16

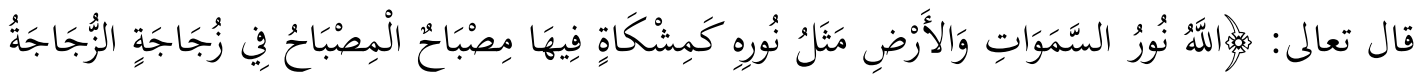

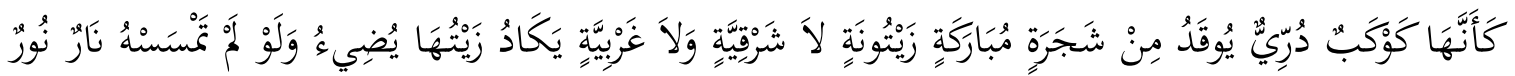

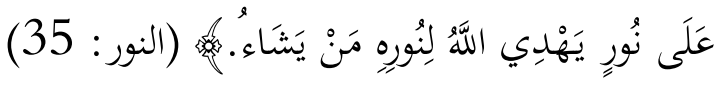

وهكذا تكون العوالم كلها منوطة بشهود أنواره على قدر مظهر التجلي. ومن أخص درجات الشهود استرسال النفس في معية الحق على الوجه الذي تحدث لها به السعادة الأبدية. وهذا هو حظ أهل الله من لذة الحضور ببقاء النظر موصولاً دون انقطاع. والخلود، على هذا النحو، ثمرة المفردين. وقد وردت الإشارة إلى ذلك قوله صلى الله عليه وسلم: "الدنيا حرام على أهل الآخرة، والآخرة حرام على أهل الدنيا، والدنيا والآخرة حرام على أهل الله" (رواه الديلمي عن ابن عباس).

16 1 الجيلي، عبد الكريع بن إبراهيه. المناظر الإلهية، تحقيق: نجاح محمود الغنيمي، القاهرة: دار المنار، 1987 م، ص234 و 235 
والنفس التي بلا كدر هي النفس التي تجلى الله عليها بأنوار المكاشفة حتى أوصلها إلى حضرة ذاته،

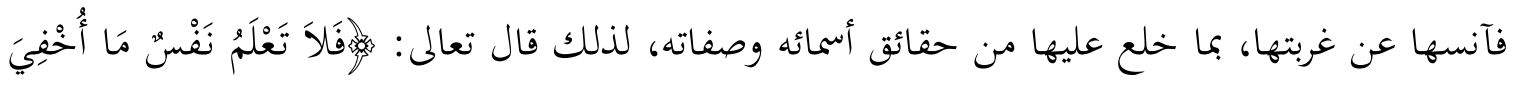

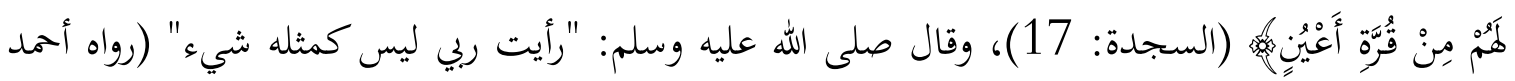
عن ابن عباس)، والتصوف، إذن، بمعنى من المعاني، هو صفاء النفس من متعلقات الزمان والمكان العارضين، وصرف التوجه عن الأغيار، ورد الهوى إلى أصل مناطه من النزوع نحو مطلق الجمال، والحضور بحقيقة ذلك من جهة نداء الحق في مقابل الغياب عن هم العدم من جهة توهم الخلق.

\section{ثانياً: الحصائص المميزة للشخصية الصوفية:}

الشخصية الصوفية الأصلية شخصية حساسة، تملك قدراً كبيراً من الرهافة والشفافية، كما إنها تملك درجة عالية من الاستجابة الأخلاقية لكل ما حولها من شفرات الكون.

ولابد أن تتولد عن الحساسية الخاصة للشخصية الصوفية خصائص بعينها تكون هي الأعمق قدرة على تحديد طبيعة الأشخاص الذين ينجذبون إلى التصوف أكثر من غيرهم وأهم هذه الخصائص فيما نرى، هي:الانطوائية، والشعور بالاغتراب، والميل إلى التأمل، والقابلية غير التقليدية للاستبصار الماورائي أو التميز بملكه الكشف، والنزوع إلى الاستبطان، والتركيز الداخلي، والقدرة على إنشاء علاقة نفسية خاصة مع الأشياء، والنفور من التجزؤ والتناهي الزماني، وطموح مجاوزة الحدود الواقعية للوجود الإنساني، ونبذ النقصان البشرى، والنفاذ المتصل من الظاهر إلى الباطن، والضيق بمظهر التعدد والكثرة، والحنين الدائم إلى الاندياح في الحقيقية الأحدية الأولى، ورؤية المفارقة بعين الاعتبار من حيث كوها مظهرا لانكشاف الحقيقة في بداهتها

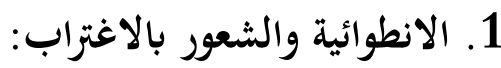

فالانطوائية خاصية تعني، في دلالتها العميقة، راحة العزلة، إنا تؤدي إلى مزيد من التجوهر، من الغوص في الداخل، ومن إيقاف الامتداد الخارجي. ولذة التوحد الصامت التي تتولد عن هذه الخاصية تتيح 
للصوي أن "يتلخص من الأنا التجريبية، وعندئذ تنبثق إلى النور الأنا الخالصة التي كانت مختبئة. 17 وتتميز هذه الأنا بسلام فريد، وباختزال الوجود كله طيها دون عناء. وهي إذ تتجلى لذاتما في لحظة إنما تحاكى بتحلى القديم تعالى لذاته بذاته حيث كان ولا شيء معه، ما تحته هواء، وما فوقه هواء، كما يقول الأثر. وهذا الاستدماج استعادة للبهاء والاكتفاء الإلهيين في كمال حقيقتيهما.

أما الشعور بالاغتراب فيعني الاغتراب عن طبيعة الواقع المتهافت، وملابسات العالم الوضيع، شعور طاغ عند الصوفي الأصيل. ومرجعه في ذلك قول النبي صلى الله عليه وسلم: "كن في الدنيا كأنك غريب أو عابر سبيل" (رواه البخاري عن ابن عمر) وسئل أحد العارفين: من الصوفي؟ فقال: "الذي لا تقله أرض، ولا تظله سماء". وأنشد بعضهم لمجنون ليلى:

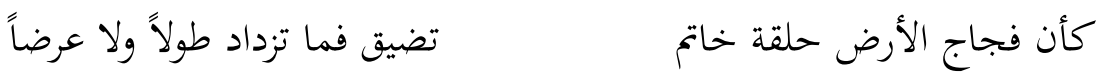

والشعور بالانتماء إلى الحقيقة الإلهية وحدها يبعل من موضوعات الحياة البشرية مثاراً للاستياء الطارف، إذا ليس هناك بين معطيات الواقع الذي يكابد الانخطاط، ويجافيه التوق إلى العلو، ما يستحق الانتماء إليه. وقال الحسين بن منصور الحلاج: الصوفي وحداني الذات، لا يقبله أحد، ولا يقبل أحداً.

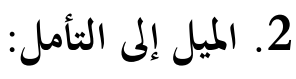

والتأمل إشراق النفس بفكرةا عند دوراها بآله البصيرة في علة الأكوان. والخواطر تقع في النفس موقع القطر فتتنعش بها النفس. والأسرار مناطها لوامع الأفكار. ولوامع الأفكار مناط النظر الدائم إلى الحكمة المتأصلة في شواهد الوجود. قال صلى الله عليه وسلم: "تفكروا في خلق الله، ولا تفكروا في الله فتهلكوا" (رواه أبو الشيخ عن أبي ذر). وخاطر الحق الهام لا ينزع إليه الباطل وإلا كان وسواساً أو هاجساً. قال إبراهيم

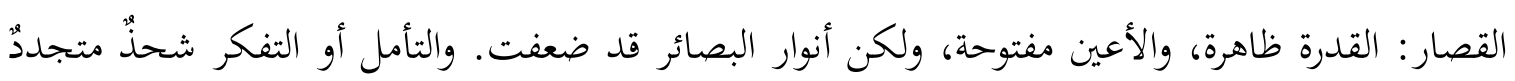
لنور البصرية، وبسط لهذا النور في المدى الحاوي لدقائق الحقائق. ويروى أنه صلى الله عليه وسلم كان طويل

$$
17
$$


الفكرة، دائم العبرة. وغالباً ما يكون التأمل قريناً للصمت والعزلة، فهما بمثابة جناحين له يحلق بكما في فضاء الموجودات، كما أن نشوة "خفية" تكاد تدفعه، دائماً، إلى استقراء الأبعد على نحو مستمر .

ويهدف التأمل عن الصوفي إلى الكشف عن أنساق التقدير الذي يتجلى من خلالما الحق للخلق بوصفه بديع السماوات والأرض، لذلك فإن التأمل، بمعنى من المعاني، وقوع على سر الإبداع الدقيق الذي يربط الكون بالمكون. قال تعال:

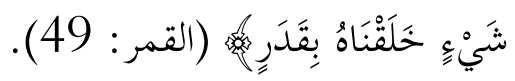

وقد يتميز أناس استثنئيون، بداية، بالقدرة على الاستبصار الماورائي وملكة الكشف ولكن مما لا شك فيه أن للرياضيات الروحية أيضاً مردوداً كبيراً في المجال، فهي تعمل على توليد الطاقة الروحية، وإنمائها، وتوجيها. والنبي صلى الله عليه وسلم نموذج فريد في ذلك، فمكاشفاته، ومشهاهداته، ونبوءاته، مما لا يدخل في نطاق الحصر، يروى عنه أنه قال: "دخلت الجنة البارحة فنظرت فيها، فإذا جعفر يطير مع الملائكة، وإذا حمزة متكئ على سرير" (رواه الطبراني والحاكم كلاهما عن ابن عباس). ويروى كذلك عنه صلى الله عليه وسلم أنه قال: "رأيت جبريل له ستمائة جناح" (رواه الطبراني عن ابن مسعود). وأنه قال: "رأيت ربي في أحسن صوره، فقال لي: يا محمد أتدرى فيم يختصم الملأ الأعلى؟ فقلت: يارب في الكفارات، فقال: وما الكفارات؟ قلت: إسباغ الوضوء في أماكنه على الكراهيات، والمشي على الإقدام إلى الصلوات، وانتظار الصلاة بعد الصلاة" (رواه الطبراني عن عبيد الله بن أبي رافع عن أبيه).

ويقول العلماء المشغولون الآن بنظرية "الاهتزاز" إن كل شيء يملك رتبة اهتزازية كونية معينة، ولكن الشكل الأثيري الاهتزازي مما يتعذر على حواسنا التقاطه، فنحن نشاهد الأشكال التي ينخفض اهتزازها إلى مادون 34 ألف موجة في البوصة الواحدة. وما يرتفع عن ذلك لا نراه. 18 وقد يكون تنشيط معين في الإنسان، عن طريق الرياضة الروحية (الصلاة، الصوم، السهر... الخ)، مسئولاً عن تفعيل القدرة الماورائية أو الكشف على نحو من الأنحاء إضافة إلى قابلية أصلية للإدراك الاستبصاري (يقال في بعض الأدبيات البارالسيكولوجية إها كامنة تحديداً في الغدة الصنوبرية). ومن الطريف

$$
18 \text { منصور، محمد منير. الموت والمغامرة الروحية، دمشق: دار الحكمة،، } 1987 \text { م، ص 226-230 }
$$


أنه يروى عن الصوفي الكبير "خير النساج" محمد بن إسماعيل السامرائي أنه كان جالساً بين أصحابه غشي

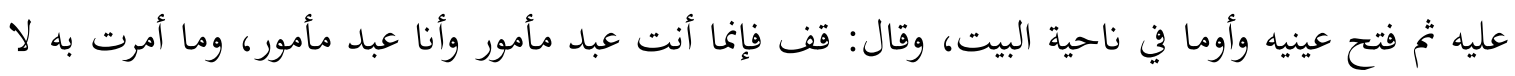
يفوتك وما أمرت به يفوتني، ودعا بماء فتوضأ وصلى المغرب ثم تمدد وأغمض عينية وتشهد ومات. 19 ويقول الجيلي في (منظر الكشف والعيان): ينفتح للعبد، في هذا المنظر، حول عينه دائرتان: ...دائرة العين الصغرى، وفيها يرى المحسوسات من وراء كثائف الحجب الحسية، أشخاصاً معينة، فلا تحجبه الجدران ولا البعد... ودائرة العين الكبرى، فيها يرى البرزخ، والملكوت، وعوالم الأرواح، ويطلع على الجن، والنيران، وأنواع النعيم والعذاب، ويعرف أجناس الملائكة... وتخاطبه الروحانيات.20

\section{3. النزوع إلى الاستبطان، والتركيز الداخلي:}

الاستبطان هو اختبار معطيات شعورنا الخاص، وبواسطته يمكن أن ندرك ونصف ما يحدث في نفوسنا: ما نرى ونسمع ونشعر ونفكر.21 ويثير علماء النفس المحدثون بعض الاعتراضات على موضوعية النتائج التي تخلص إليها عملية الاستبطان، ولكن هذه الاعتراضات تمثل مشكلة إجرائية خاصة بكم وحدهم، كما أن هذه الاعتراضات لا تنال، باعترافهم، من مصداق الظاهرة نفسها. والشخصية الصوفية تعول على الاستبطان كثيراً، وبتعل من التركيز الداخلي محوراً للنشاط الاستبطاني المتصل. وقد يكون من حق الصوفي أن يعيد تعريف مفهوم الاستبطان، تبعاً لسياق بحربته الخاصة، على أساس من كونه نفاذاً إلى الأعماق الداخلية للذات من أجل إدراك الموية الشعورية لما، ووصفها على ما هي عليه من تناغم فطرى مع المطلق أو المتعالي.

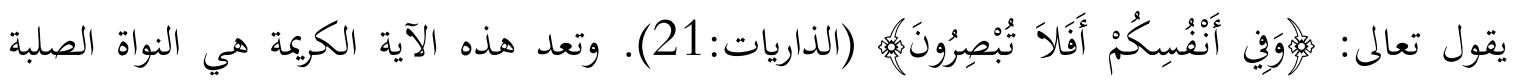
لدعوة الإنسان إلى الغوص في أعماق ذاته بهدف الوقوع على سر المعنى في الحديث الشريف: "خلق الله أدم على صورته" (رواه أحمد والبخاري ومسلم كلهم عن أبي هريرة).

$$
\begin{aligned}
& 19 \text { } 19 \\
& 20 \\
& 21
\end{aligned}
$$


لاحظ فيلسوف مثل "كير كجارد" أن الفكر هو الداخلية، والداخلية هي الذاتية، والذاتية هي أساساً هوى.22 هذا الهوى، في صميمه، هو الوحيد، من منظور الصوفي، في جدارته بأن يكون مناطاً للإشراق النوراني. وذلك باعتبار كونه محاكاة لحالة الوجود الإلهي نفسه حال اتصافه بالبطون (وهي المرتبة الإلهية التي تعرف بالهاهوت)، وعليها وقعت الإشارة في الأثر المشهور : "كنت كنزاً مخفياً في الحضرة العمائية فأحببت أن أعرف فخلقت الخلق فبي عرفوي."

بمعزل عن التشويشات التي يلدها الامتداد السطحي نهو الخارج، يحدث الانقباض نحو الداخل في عملية الاستبطان، بحيث يشبه الكائن صدفة تستدير على ذاتا لتتأمل دون تطفل لؤلؤة أسرارها. وينبثق، دوماً، رهان مزدوج، أثناء هذا النشاط الوجداني، على جمعية الإنسان على ذاته الحقيقية، وجمعية ذاته الحقيقية على الله. وهاتان الجمعيتان، في واقع الأمر، وجهان لمعدن واحد نفيس، لا بععنى أن ذات المرء الحقيقية وذات الله تعالى ذات واحدة، ولكن بمعنى أن هذه مرآة تلك. وهذا ما عناه الحلاج بقوله:

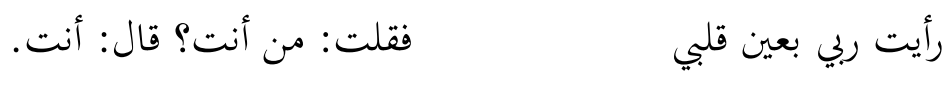

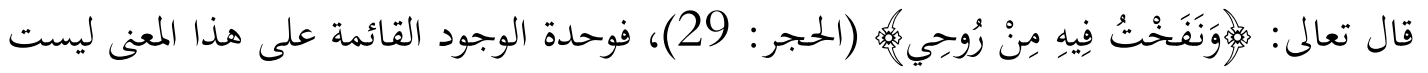
وحدة ماهية أو ذات، بل وحدة صفات دار حولها قوام الوجود في حاجته إلى التدبير والقيومية.

\section{4. القدرة على إنشاء علاقة نفسية خاصة مع الأشياء:}

ولا يعني فراغ الصوفي، بالضرورة، من الأغيار فراغه من الأشياء. بيد أن علاقة الصوفي مع الأشياءلا تقوم على مادة الأشياء، بل على إيحاءات الأشياء، وهذه الإيحاءات تصب، قطعاً، في مجرى بتربته بحيث تثرى إبعادها، وتصقل من دلالتها. الأشياء، هنا، علامات signs أو رموز تحيل، في النهاية، إلى مرموزها

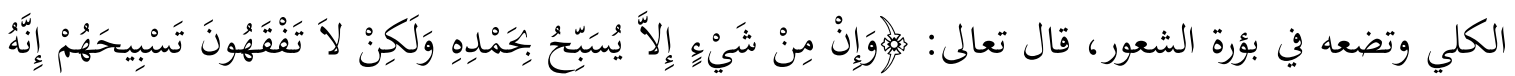
كَانَ حَلِيمًا غَفْورًا (الإسراء. عينيه بحال الأشياء في حراكها أو سكوها": حفيف الأوراق، زخات المطر، تصفيق الرياح، هدير الموج،

$$
22
$$


خفق الأجنحة، أنين القصبة، ارتطام الحجر، دوران الطاحونة أو الساقية، طقطقة النار، أزيز النحل.. الخ" حيث يعمل المظهر النفسي للعلامة.. أو الرمز في شكله أو إيقاعه -استدارة القوقعة، الخناء النخلة، رقصة السرب، تدويم الفراشة.. الخ- على تأصيل تنويعات الاستجابة الشعورية إزاء تعدد بتليات المطلق بصفاته المختلفة وأسمائه المتباينة -الجميل، الجليل، النافع، اللطيف، الحي، الزكي، البديع، المحيط.. الخ- في مظاهر الطبيعة الكونية اللامحدودة. لذلك سبح الحصى في كف النبي صلى الله عليه وسلم وحن إليه الجذغع على المنبر، وألقى عليه حجر بمكة السلام، ودرت ضرع الشاة العجفاء بين يديه اللبن، وليس هذا فقط من قبيل خرق العادة على هيئة معجزة، ولكنه، كذلك، انفعال الأشياء لمن آنسها، وأدرك لغتها المضمرة، وتواصل معها تواصلاً حميماً يفتح إمكاناتحا على أفق المقدَّس والمطلق والمتعالي.

ويروى عن سمنون بن حمزة المحب أنه تكلم يوماً في المحبة، وكان بسقف المسجد ثريات وقناديل فتحركت ثم أخذت تصطفق حتى تكسرت ووقعت في صحن المسجد، كذلك يروى أن سهل بن عبد الله جلس يوما بين أصحابة فوقع حمام في المسجد من شدة ما لحقه من الحر والمشقة فنظر إليه سهل ثم قال أن ترك أخى شاه الكرماني مات الساعة، فكتبوا في ذلك فكان كما قال.

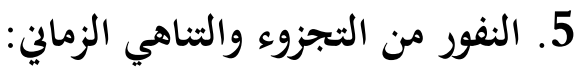

والزمان في نظر الصوفي هو الديمومة. وقال أبو يزيد البسطامي: أوقاتكم مقطوعة ووقتي ما له طرفان. هكذا ينفر الصوفي دائماً من التجزؤ، والتناهي، لأغما علامتان من علامات النقصان. وكثيراً ما يقال إن الصوفي ابن وقته ومن معاني ذلك، فيما أرى أن الصوفي ابن اللحظة التي يشهد امتدادها داخله. وهذا الامتداد لا حد له لأنه يجعله متدفقاً في الدهر. قال صلى الله عليه وسلم: "لا تسبوا الدهر، فان الله هو

$$
\text { الدهر" (رواه مسلم عن أبي هريرة). }
$$

يعني التجزؤ تبعثر الوجود الشخصي من حيث زمنيته "ماضي وحاضر ومستقبل" بينما يعنى التناهي توقف هذا الوجود نفسه عن تمثل معناه في صورة حية متحركة. والأمران كلاهما يولدان صدعاً في بنية الشعور من حيث كوهما انكشافاً أصيلاً يعكس، في بعده الميتافيزيقي، مظهر الكلية الأبدية لله، شكلها، وإيقاعها، ودلالتها. الصوفي، إذن يشدد دوماً، على ارتباطه بالكلية والديمومة الإلهيتين بوصفه وسيطاً لتجليهما، يقول 
الحلاج رحه الله: "ما انفصلت البشرية عنه ولا اتصلت به"، 23 ومن هنا كانت جزئية الإنسان صفة أو شرطاً باعتبار العبودية فقط.

$$
\text { وتحسب أنك جرم صغير وفيك انطوى العالم الأكبر. }
$$

والحقيقة أن الإنسان كُلٌّ باعتبار قابليته لتجلي الكل من خلاله. كذلك كان الإنسان متناهياً باعتبار ضرورة زوال عرض الوجود المستقبل بذاته فقط. والحقيقة أن الإنسان لا متناه باعتبار تعلق جوهر وجوده بالوجود الإلهي. ولذلك كان الموت انتقالاً من أحد أشكال الحياة إلى شكل أخر لها، له قوانينه الأخرى ولم يكن ولوجاً في ظلام العدم الدامس كما يدعى الماديون من الفلاسفة، وقد أدرك بعض المحدثين نباهة الفكرة التي تقوم على فهم الزمن بما هو حاضر دائم، ولاحظ كثير منهم أن النظر إلى الزمن على أساس من كونه طولياً linear - بدلاً عن كونه دائرياً - circuit ويمشي في ابتاه واحد يؤدى إلى اختلاف الإنسان. 24 وهذه الملاحظة تدل، في جوهرها، على أن التوافق النفسي-البيولوجي للكائن البشرى يتحقق بتوافق الاستنتاج الذهني مع الحقيقة التي اكتشفها الصوفي المسلم قبل بتربة الهولوجرام وكلام عدد من علماء الفسيولوجيا العصبية عن بقاء العقل بعد تحلل الجسم، بزمان طويل.

والزمان والمكان اللذان نعرفهما تحديداً ليسا أكثر من وهمين كما يقول فيزيائيو (الكم). ومن هنا فليس هناك ما يمنع أن ننظر بعين أخرى إلى الزمان ما دام هذا النظر يحقق قياساته في مستوى ذواتنا. إن هناك إمكانية قائمة لوجود الزمن الدائري ما دام فاصل ما يظل يفصل بين عالم الظواهر وعالم الحقائق. ومن الخطأ البين أن نتصور خلطاً بين الوعي البدائي الأسطوري بالزمن والوعي الصوفي به، فكل من الوعيين يعمل على مستوى مختلف من الآخر. إن الأول مسكون بعالم المادة، والثاني مسكون بالعالم الأثيري. وقد يصح كون المادة أثيراً في درجة اهتزازية منخفضة نسبياً. وحقيقة الزمن المطلق، إذن تكمن في درجة اهتزازية قصوى تخرج عندها المادة عن حدودها المادية كي تتحول إلى طاقة. إن المادة هنا تفقد نفسها. وعلى ترك

$$
\begin{aligned}
& 232 \\
& \text { الكتب العلمية، } 1998 \text { م، ص } 239 \\
& 24
\end{aligned}
$$


نهو مجازى ما، ربما يفقد الصوفي نفسه، فقد مشى رجل من أتباع ذي النون خلف أبي يزيد البسطامي، فلما

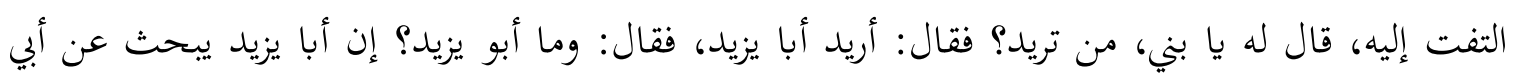
يزيد منذ أربعين سنة، فما شم له رائحة، فلما أن بلغ ذلك ذا النون بكى بكاءاً شديداً، وقال: أن أخي أبا يزيد ذهب مع الذاهبين. ولعل هذا الفقدان، عند الصوفي، هو عين الوجود ذاته بما له من صفتي الكلية، والديمومة. إنه هدم للوجود الشخصي النسبي بتجزؤه وتناهيه من اجل إفساح أفق الزمن الدهري للوجود المتعالي. ومن خلال تعلق هذا المحو بذلك الإثبات أو تعلق الخلاء بذلك الملاء يكتسب الأولى معنى الثاني، ويصبح مفعماً به من جميع أطرافه.

\section{6. طموح مجاوزة الحدود الواقعية للوجود الإنساتي:}

يؤرق النقصان البشرى الصوي بشدة. لذلك فهو يطمح إلى مجاوزة هذا النقصان عن طريق الاتصاف بالكمالات الإلهية. "والإنسان الكامل" فيما يقول الجيلي، هو القطب الذي تدور عليه أفلاك الوجود من أوله إلى أخره، وهو واحد منذ كان الوجود إلى أبد الآبدين، ثم له تنوع في الملابس.. وله في كل زمان اسم ما يليق بلباسه في ذلك الزمان.. وقد جرت سنته صلى الله عليه وسلم أنه لا يزال يتصور في كل زمان بصورة أكملهم ليعلي شأفم ويقيم ميلافم، فهم خلفاؤه في الظاهر وهو في الباطن حقيقتهم. 25 وفي الحديث القدسي ".. وما يزال عبدي يتقرب إلي حتى أحبه، فإن أحببته كنت سمعه وبصره ويده" (أخرجه بن عسكر عن انس) وجاء في الأثر. "عبدي أطعني أجعلك ربانياً تقول للشيء كن فيكون."

لعل "الحضور المتسامي" أو العلو بالمصطلح الفلسفي هو الحنين الداخلي المتصل إلى اختزال الكينونة الشخصية في نفخة الروح الأولى التي أودعها الله تعالى قصبة الإنسان. والتصوف بمعنى من المعاني، هو تصفية الكيان الإنساني من العوالق البشرية المتراكبة وصولاً إلى هذه النواة الرئيسية الكامنة في العمق. وبالوصول إليها يكون الإنسان قد تخلص تماماً مما سوى الحق المحض في تكوينه. وهكذا يجاوز حدوده الواقعية إلى لا حدود الكمال الأعظم. ونهن نجد فيما يعرف "بالشطح" أمثلة طارفة على استشراف ذلك الأفق اللغز والوثوب إلى ميدانه. ويعمل حال "البسط" النفسي لدى الصوفي على تسهيل اقتحامه لتلك الدائرة من جهات عديدة.

25 2 
سئل الحلاج يوماً: من أنت؟ فقال: أنا الحق، بينما أخذت الشبلي سكرة من سكرات الوجد فأفصح عن مكنونه قائلاً: أنا النقطة التي تحت الباء "وهي التي تعرف باسم نقطة البقاء". وللسهلجي بإسناد مظفر بن عيسى المراغي قال سمعت "شنبين" يقول: سمعت أبا موسى الديبلي يقول: سمعت أبا يزيد البسطامي يقول: غيب معروف، وشهود مفقود، وأنا في الغيب محضور، وفي الشهود موجود. وقال مرة: انتهى الأمر إلى يلى بركي كما شأنى وقد انتهى إلى غاية كماله.

وقد يرى البعض أن طموح "الحضور المتسامي" أو "العلو" يخفى مفارقة جوهرية حداها الرئيسيان هما: الاغتراب، والنرجسية. بيد أن هذه المفارقة، في الحقيقة، تنبثق على مستوى السطح فقط، فعلى مستوى العمق الأصيل للشخصية الصوفية، حسب ما أرى، يجرى تيار داخلي أبعد من ذلك كثيراً، ويتسم هذا التيار الأبعد بنزوع نفسي متزايد إلى المثالية الجمالية في عنصرها الأسمى: المطلق الذي يختصر في قيمة وجوده الذاتي كل إمكانية متاحة، وهذه المثالية الجمالية تحتوي طيها معنى متعالياً يتعدى أشكاله النسبية، ويتخطاها نهو صفة مشتركة بين الحق والخلق وهي الربوبية.

\section{7. - النفاذ المتصل من الظاهر إلى الباطن:}

وللشخصية الصوفية نزوع واضح إلى الاعتقاد في مستويين من الحكمة، وإلى الرهان على المستوى المضمر منها، أي أن لها شغفاً خاصاً بالولوج إلى السر. فالظاهر والباطن تعبيران مألوفان عن الشريعة والحقيقة، والله تعالى هو الظاهر والباطن باعتبار بتلياته الصفاتية. وفي الأثر أن لكل أية ظاهراً وباطناً وحداً ومطلعاً، كما أن الظاهر مدلول العبارة، والباطن مدلول الإشارة، والإشارة تضفو على العبارة، وتفيض عنها. ويقول "الهجويري" رمه الله أن الحقيقة تدل على حكم لا يقبل النسخ، والشريعة تشمل الحقيقة

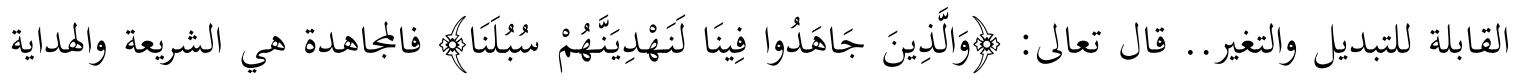
هي الحقيقة... فالشريعة من المكاسب أما الحقيقة فهي من المواهب. 27

26 مبدوي، عبد الرمن. انظر "النور من كلمات أبي طيفور للسهلجي" في كتاب شطحات الصوفية، الكويت: وكالة المطبوعات 1978 م، ص 129 المرجع السابق، ص 145 
ونستطيع القول بأن الحقيقة هي المبدأ الأصلي الكامن وراء تجلياتها الزمنية، التي تمثل، بدورها الشرائع

والمواثيق الإلهية. وهذه الحقيقة تمتلك معنى من معاني الأسرار باعتبار كوها صورة لمعرفة الله تعالى. ومعرفة الله تعالى تنطوي على أبعاد تدرك بعضها الخليقة بينما لا يدركون بعضها الآخر لاختصاص فئة من ذوى البصيرة الاستثنئية به. قال صلى الله عليه وسلم "علم الباطن سر من أسرار الله عز وجل وحكم من حكم الله يقذفه في قلوب من يشاء من عباده" (رواه الديلمي عن علي). وقال القشيري رمه الله: الشريعة أن تعبده، والحقيقة أن تشهلده.

للصوفي، إذاً، حركة دائمة من حال العبودية إلى حال الشهود. والشهود، فيما يقول الكاشاني، رؤية الحق بالحق، ومنها شهود المفصل في المجمل أي رؤية الكثرة في الذات الأحدية وشهود المجمل في المفصل أي رؤية الأحدية في الكثرة. 28 وهذه الشعبة من علم معرفة الله تعالى شعبة دقيقة تعز على سواد الناس، ولكنها تحتوى دقائق ولطائف كثيرة عند ذوي البصيرة العالية من خواص العارفين. يضرب الصوفي في أعماق موغلة حين يلج علم الباطن أو علم الحقيقة، ويشي هذا المسلك الخطر بانخطاف روحي فريد نهو استهلاك الذات في نشوة محرقة تفجرها معرفة فوق عادية. وهذه المعرفة تقوم على رفع الحجاب بين الخالق والمخلوق باعتبار

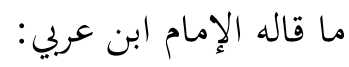

\section{جمع وفرق فان العين واحدة وهي الكثيرة لا تبقي ولا تذر 8. الحنين إلى الاندياح في الحقيقة الأحدية الأولى:}

وثمة نفور ملحوظ عند الصوفي من التعدد والكثرة يقابله حنين جارف إلى الاندياح في مكنون الأزل الساكن المتدفق في ذاته والمتجلي عن ذاته لذاته بذاته، في مرتبة الأحدية المطلقة.

إذا استدعيت إلى حقل الميتافيزيقا لغة الفيزياء فسوف أقول إن النفور من الكثرة، في أساسه، نفور من

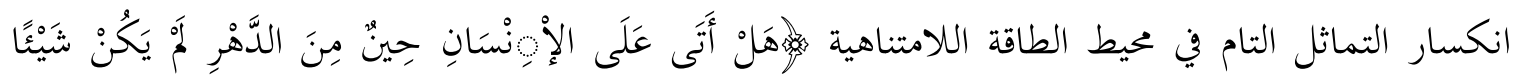

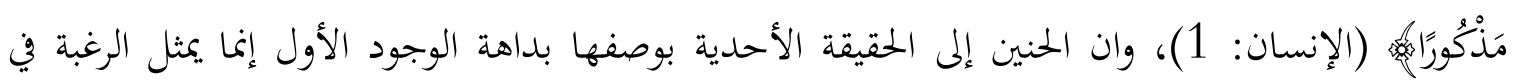
28 الهجويري، أبو المسن علي بن عثمان. كشف الخبوب، ت: عمود أممد ماضي أبو العزايع، القاهرة، دار التراث العربي، 1974 م، ص 466,465 
استمرار التوازي، أي في الطيّ في مقابل النشر. وهو ما عبر عنه عمر بن الخطاب رضي الله عنه عند سماعه الآية الكريمة بقولة: ليتها تمت.

$$
\text { إن هناك مناوءة نفسية للنشأة، ومدافعة للقالب الذي سجنت فيه الروح الإنساني. }
$$

إن اللا إيجاد كالموت هو أحد التصورات المطمئنة، أحياناً، لاستمرار الكنون بما يعنيه من السباحة اللاواعية، والسعيدة، في فضاء اللاغاية المطلقة، والسعادة المقصودة لا تشترط الوعي لأها لا تقترن بالشعور بل تقترن في مفهومها غير الذاتي بفطرة غفل تماماً، عمادها تبعية الحركة الموجية الجزئية للإيقاع الكلي الذي يفترض حتميته. لذلك كان أحد الصوفية يدعو فيقول: اللهم كن لي بما كنت لي من قبل أن أكون.

ومرتبة الكثرة، عند طائفة الصوفية، هي مرتبة الواحدية. وهي تعبر عن الحقيقة الآدمية حيث بحلى الله عن ذاته بغيره لغيره. ولعلنا ندرك، في هذا السياق، أن النفور من الكثرة نفور من الزمن التاريخي. وإذا كان التغير هو الذي يجلب الزمن فإن أساس النفور هنا هو الاستياء الشعوري من التغير والتحول، من الصيرورة. إن الصوفي منجذب دائما إلى الكينونة في مقابل الصيرورة.

يبدو أن الإنسان قد عرف نسبته إلى ذاته منذ عرف الزمن. في اللازمنية الأولى كانت نسبة الإنسان إلى الله أو الدهر هي الأجدر بالصواب لأن الإنسان لم يكن إلا معنى في عالم القوة لا الفعل: معنى معلقاً على المشئية الإلهية فحسب. إن "السوى"، حتى لو كان إمكاناً من إمكانات التجلي في مرآة، لم يكن له وجود. ومن ثم فهو فكرة تتبع، في حيادها الاحتمالي مد الأفكار النواسة اللامتناهية التي هتنز كرعشات الأوتار في العقل الكلي. أما وقد أصبح الإنسان هو الغير فقد صار مهدداً بنسيان عتبة المعنى الذي ينتمي من خلاله إلى ما لا ينتمي إليه الآن من حيث رسمه وظاهره. وهذا هو مصدر الخوف والقلق والشعور بالخسران والغيرة. 
يألم الصوي بمفارقة الوجود كما لا يألم، فيما أرى، بشيء أخر. وهذا هو السبب، ربما في تقلب الصوفي، تقلباً تَّصِلاً، بين القبض والبسط، وبين الصحو والسكر، وبين الجمع والفرق، وبين المحو والإثبات.. وهكذا.

يقول أحمد بن فاتك: سمعت الحسين بن منصور يقول: ليس على وجه الأرض كفر إلا وتحته إيمان، ولا طاعة إلا وتحتها معصية ولا إفراد بالعبودية إلا وتحته ترك الحرمة، ولا دعوى محبة إلا وتحتها سوء أدب. 29 وكتب الحلاج إلى "جندب بن زادان الواسطي" وكان من تلاميذه:.. ظاهر الشريعة كفر خفي، وحقيقة الكفر معرفة جلية.. أوصيك أن لا تغتر بالله ولا تيأس منه ولا ترغب في محبته ولا ترضى أن تكون غير محب، ولا تقل بإثباته ولا تمل إلى نفيه.. والسلام. 30

ويقول النفري رممه الله في (موقف ما يبدو): أوقفني فيما يبدو فرأيته لا يبدو فيخفى ولا يخفى فيبدو ولا معنى فيكون معنى، وقال لي: قف في النار، فرايته يعذب بها، ورأيتها جنة، ورأيت ما ينعم به في الجنة هو ما يعذب به في النار. 31 ويقول في مخاطبته الرابعة عشرة: يا عبد حجاب لا يكشف، وكشوف لا يحجب: فالحجاب الذي لا يكشف هو العلم بي، والكشوف الذي لا يحجب هو العلم بي. 32 وإذا كان الله تعالى هو المفارق الأسمى باعتبار الكنه أو باعتبار الهاهوت (بطون البطون) لقدمه وحدوث العالم، فان "ابن عربي" رمه الله يرى أن الله (باعتبار مرتبتي اللاهوت والناسوت) حق في ذاته، ركا وخلق من حيث صفاته، وهذه الصفات نفسها هي عين الذات، "سبحان من أظهر الأشياء وهو عينها."

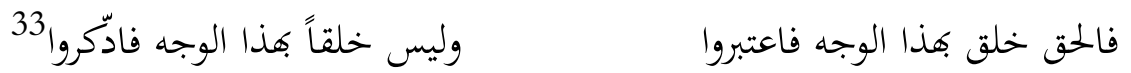

2929

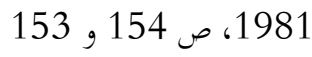

$$
\begin{aligned}
& 30 \\
& 31 \\
& 32 \\
& 33
\end{aligned}
$$


ونخن نلاحظ من كل ما سبق أن المفارقة هي مظهر انكشاف الحقيقة في بداهتها الأولية. والصوفي

المسلم في واقع الأمر، قد درج على عدِّ المفارقة نواة لتعرف الإنسان على الوجود، وتفكره فيه. وهو ذاته شخصية متقلبة على داخليتها، تكابد الشعور بالمفارقة على مستوى نشاطها النفسي عادة. وتجاوب الشعور والفكر، على هذا النحو الفريد، ينُّ عن حساسية سلوكية خاصة ينصهر، من خلالها، الوجداني والعقلي في بوتقة واحدة كي يشكلا موقفاً كلياً من الوجود عماده التقابل بين الثنائيات التي تنتظمها وحدة مكتملة

ومما لا شك فيه أن "المفارقة الأم" تكمن في نظرية التوحيد الخاص أو "وحدة الوجود" حسب الاصطلاح المشهور، فالعالم ليس إلا المرآة التي تنعكس عليها الأسماء الإلهية، وتتحقق فيها الأعيان الثابتة التي هي موجودات معقولة في الذات الإلهية، ولكنها معدومة في الوجود الخارجي وهي ماهيات باعتبارها صوراً، وهويات باعتبارها تعينات.34 وتتشعب عن هذه "المفارقة الأم" سائر المفارقات الفرعية الأخرى بعد ذلك، فالتفارق مناط ظهور القديم في الحادث، ورجعى الحادث إلى القديم. ورؤية المفارقة تعتمد في أساسها على إدراك ما لذلك المد الوجودي المتصل من تعارضات الصفة والتأثير. وذلك بمقتضى سنة الله في العالم من تدافع العناصر والمخلوقات والأشياء.

\section{ثالثاً: الدوافع النفسية إلى التصوف وفقدان الشعور بالثناغم:}

من الأصوب دائماً أن ننظر إلى التصوف بوصفه فاعلية نفسية إيهابية بدلاً عن أن ننظر إليه بوصفه خللاً أو علة مرضية تتطلب علاجاً. وذلك لأن أكثر من نظروا إليه من منظور العلة أو المرض، لم يستطيعوا أن يجيبوا عن سؤال: لماذا ينجح الصوفي، ولو من خلال ممارسته العملية، في أن يصوغ رؤية متكاملة الأبعاد للحياة أو الوجود الإنساني في أبعاده الروحية؟ وهل يملك من يعانى الجنوح النفسي أو الاضطراب العصبي والوجداني هذه المنهجية المتسقة؟ بيد أن عدالة النظر إلى ظاهرة التصوف لا تحول دون احتمالية تدخل بعض كر بـ الدوافع النفسية القوية في توجيه شخصية ما ذات حساسية ما نهو التصوف. وذلك شأن تشكيل الدوافع النفسية بدرجة من الدرجات لأي ظاهرة من الظواهر. وتصب أغلب هذه الدوافع في مجرى واحد هو فقدان

$$
34
$$


الشعور بالتناغم، والتوجه الصوفي، في أبرز دلالثه النفسية، هو السعي إلى امتلاك هذا الشعور بالتناغم، وإنمائه إلى درجته القصوى.

$$
\begin{aligned}
& \text { وفيما يأتي ذكرٌ لأهم الدوافع النفسية التي ربما تكون سبب التوجه الصوفي مع التمثيل لها: } \\
& \text { 1- العجز عن التكيف مع الواقع الاجتماعي العاري من القيم. }
\end{aligned}
$$

قال أبو علي الدقاق "كان سبب زهد داود الطائي أنه كان يمر ببغداد فمر يوماً فنحاه الناس عن الطريق بين يدي حميد الطوسي، فالتفت داود فرأى حميد فقال داود: أف لدنيا سبقك بها حميد، ولزم البيت

$$
\text { وأخذ في الجهد والعبادة. } 35
$$

\section{2- 2 الاغتراب الناتج عن فقدان التوافق مع الآخرين:}

قال إسحاق بن أحمد: حدثنا الأزرقي قال: لما انصرف أبو موسى الأشعري من الحكمين نزل مكة، فبنى سقيفة من حجارة على فوهة شعب أبي الدب، وهناك مقبرة، فقال: أجاور قوماً لا يغدرون، يعني أهل القبور.

\section{3- 3 التوحد الناتج عن التعرض لتجارب محبطة:}

يروي صاحب الطبقات الكبرى أن علي زين العابدين بن الحسين بن علي لما قتل أخوه علي الأكبر يوم كربلاء كان عمره ثلاث عشرة سنة، إلا أنه كان مريضاً نائماً على فراش فلم يقتل. وحمل إلى عبد الملك

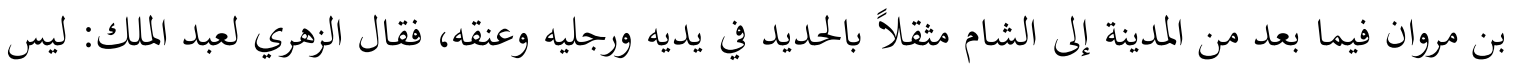
علي بن الحسين حيث تظن من جهة الخلافة إنما هو مشغول بنفسه، وبعبادة ربه عز وجل. فقال: نعم ما شغل به نفسه. وأطلقه. لذلك كان يقول: "فقد الأحبة غربة". وكان يصلي في كل يوم وليلة ألف ركعة.

$$
36 \text { 35 } 35
$$


وكانت الريح تيج فيخر مغشياً عليه. 37 وتفرغ مدة عمره كلها لعمران باطنه بالعبادة، والزهد والصبر على الأذى، مؤثراً العزلة، والابتعاد عن الحوض في أمور العامة.

\section{4- الاستغراق الباطني الذي يولده تأثير حوادث غريبة مفاجأة:}

قال المغربي لذي النون: يا أبا الفيض ما كان سبب توبتك؟ قال: عجب لا تطيقه. قال: بمعبودك إلا أخبرتني فقال ذو النون: أردت الخروج من مصر إلى بعض القرى فنمت بالطريق في بعض الصحارى، فقتحت عيني فإذا أنا بقنبرة عمياء سقطت من وكرها على الأرض، فانشقت الأرض وخرجت منها سكركتان "انيتان صغيرتان" أحداها ذهب والأخرى فضة ويف أحداهما سمسم وفي الأخرى ماء فجعلت تأكل من هذا وتشرب من هذا، فقلت: حسبي قد تبت. ولزمت الباب إلى أن قبلني الله عز وجل. 38

ومن ذلك أيضاً ما حدث لإبراهيم بن أدهم عند خروجه للصيد، وما حدث للفضيل بن عياض عند

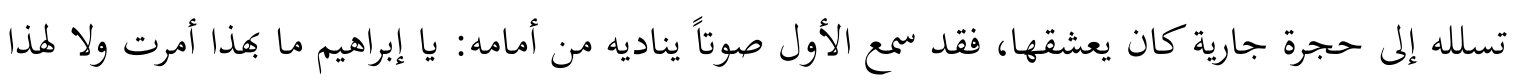

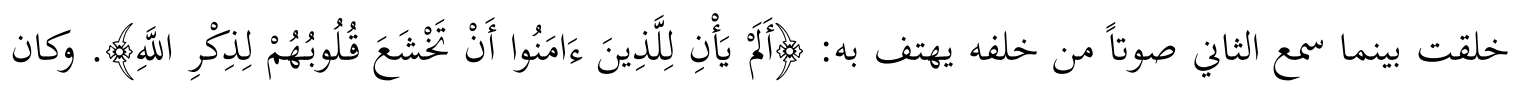
رد فعل سماع الصوت الغريب عند ابن أدهم أنه خلع ثياب ملكه، وهام على وجهه في البادية بينما كان رد فعل بن عياض أن انطلق إلى مكة فجاور الحرم حتى مات.

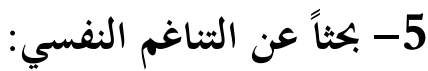

يشير تحديد أقوال كثير من الصوفية، خاصة ما يخص منها بدايات السلوك، إلى أن التناغم النفسي مطمح من أهم المطامح لدى الراغب في الطريق. وفقدان التناغم النفسي قرين دائم للقلق والحيرة والخوف والأسى والشوق بما هي مظاهر تحول دون الشعور بالألفة والأمان والإشباع الشعوري. ومن ثم فان البحث رتث

البستي، الحافظ أبو سليمان بن أمد بن معمد بن إبراهيم الخطابي. العزلة، تحقيق: عبد الغفار سليمان البنداري، بيروت: دار الكتب

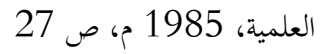
الشعراني، عبد الوهاب. لواقح الأنوار في طبقات الأخيار، تحقيق عبد الرمن حسن عمود، ج 1، القاهرة: مكتبة الآداب، 1993 م، ص 89، 90 
الدؤوب عن مصدر للدفء، ووسادة للأمان، ومعين للاكتفاء والرضا، هو محور المكابدة الصوفية، وقطب رحاها الدوار.

كما تدل الأقوال الصوفية على تلوينات الأحوال التي تعترى الصويف، وتحرمه الطمأنينة و الغبطة. والصوفي كذلك لأنه يظل يقطع العلائق بينما تحاول أن تشغله حتى يصل إلى مقام تمكينه. وهنا ينفتح باب من السلام الدائم مع الذات والكائنات والأشياء حيث الحياة بالله. والحضور في الله، والمشاهدة لله. وهذا السلام ثمرة "استرسال النفس مع الله على ما يريد، والجلوس معه بلا هم "كما يقول العارفون الكبار. وهم

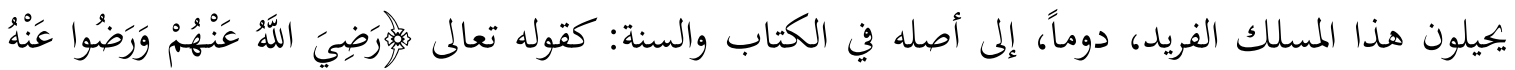

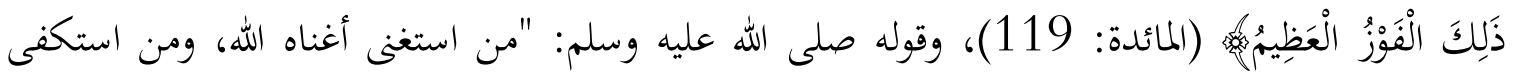
كفاه الله" (رواه أحمد والنسائي عن أبي سعيد)، وقوله صلى الله عليه وسلم: "من أصبح وهمه غير الله فليس من الله" (رواه الحاكم عن ابن مسعود)، وقوله صلى الله عليه وسلم: "من اتقى الله وقاه كل شيء" (رواه ابن النجار عن ابن مسعود)، وقوله صلى الله عليه وسلم: "من سره أن يكون أقوى الناس فليتوكل على الله" (رواه ابن أبي الدنيا عن ابن عباس).

الرضا، والاستغناء، والتقوى، والتوكل، إذن، مدار استرسال النفس مع الله على ما يريد، والجلوس معه

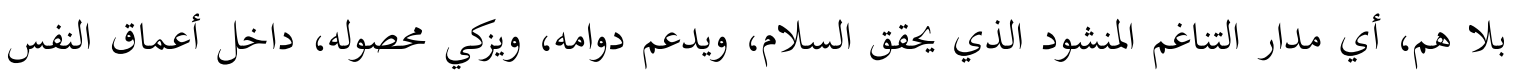
الإنسانية، لأن جذور هذه النفس موصولة، في واقع الأمر بهذه الخصال وأشباهها. لذلك قيل: "من عرف رئ

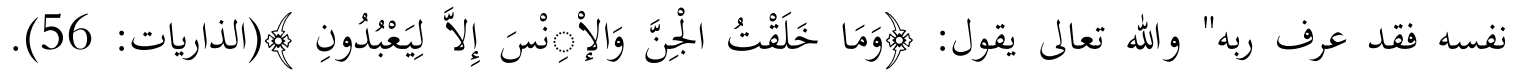
والعبادة تفريد المعبود على الوجه الذي يليق به. ومن هنا جاء في الأثر: "من جعل همه هماً واحداً، كفاه الله تعالى سائر الهموم: وجاء في الحديث القدسي: "يا بن آدم تفرغ لعبادتي أملأ قلبك غنى، وأملأ يديك رزقاً، يا بن آدم لا تباعد مني فأملأ قلبك فقراً وأملأ يديك شغلاً" (رواه الطبراني والحاكم عن معقل بن يسار). إن الدخول في ما يسمى المجال الحيوي للإنسان هو الخطوة الأولى لإعادة التوازن إلى النفس، ومن ثم إلى الجسم ذاته، خلاياه وذراته، والإيمان بالفكرة، والتفاعل معها، في هدوء، مرة تلو أخرى، يصل بالمرء إلى أعماق ذاته، تنساب، عبرها، تلقائياً، رسالة بلغة سرية تنطوي على علاقة جديدة حية بين موجات العقل 
وموجات الكون. تتشكل هذه العلاقة بوصفها مجالاً متجاوباً من الترددات التي تنقي المشاعر من جانبها الضار "القلق، الخوف، الأنانية، السخط، الغضب، الضغينة" وتحولها إلى طاقة موجبة، تتحول بدورها إلى مادة ملموسة تنفعل لها الأشياء ذاها في عالم الحس. وهكذا يحدث التناغم المنشود في حده الأقصى عن طريق التوحد الكامل مع الإرادة الإلهية "القضاء والقدر" دون غصة تشوب هذا التوحد. التناغم، إذن، عين التسليم لمراد الحق. والصوفية يقولون إن التسليم، على هذا النحو لمراد الحق، يورث إقرار الحق لمراد العبد، لأن محبة الله تعالى لعبده ثمرة رضا عبده به وعنه. ويسمون هذا المقام العالي "مقام التصريف" وهو مقام "كن" وهو للنبي ومن على قدمه من كاملي العارفين، ومثاله قوله صلى الله عليه وسلم "لمن رآه المسلمون الناشطون إلى الغزو يعدو بعيداً، من ورائهم، دون راحلة ليلحق بهم فلم يتبينوه من هو، كن أبا ذر. فلما دنا قالوا: هو له و الله أبو ذر". ومثاله أيضاً قوله صلى الله عليه وسلم: لعمر رضي الله عنه: عش حميداً ومت شهيداً. فكان ذلك كذلك.

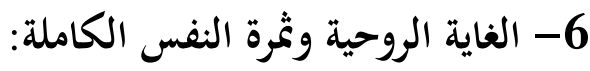

لابد أن الغاية من الطريق الطويل والشاقّ للتصوف هي الوصول إلى النفس الكاملة. وهذه النفس هي المقام السابع والأخير من مقامات الصوفية السبعة" أماره، لوامة، ملهمة، مطمئنة، راضية، مرضية، كاملة"، وعالمها كثرة في وحدة، ووحدة في كثرة، ومحلها الحنفاء، وحالها البقاء، وواردها الشريعة والطريقة والمعرفة والحقيقة.

وقال الإمام عبد القادر الجيلاني في غوثيته المعروفة: قال الله تعالى: "يا غوث الأعظم" قلت: "لبيك يا رب الغوث"، قال: "كل طور بين الناسوت والملكوت فهو شريعة، وكل طور بين الملكوت والجبروت فهو طريقة، وكل طور بين الجبروت واللاهوت فهو حقيقة"، ثم قال لي: "يا غوث الأعظم ما ظهرت في شيء كظهوري في الإنسان.. يا غوث الأعظم جعلت الإنسان مطيتي، وجعلت سائر الأكوان مطية له.. يا غوث الأعظم الإنسان سري وأنا سره.. يا غوث الأعظم رأيت الأرواح يتربصون في قوالبهم بعد قوله "ألست 
بربكم" إلى يوم القيامة.. يا غوث الأعظم اخرج عن عقبة الدنيا تصل بالآخرة واخرج عن عقبة الآخرة تصل إليّ.. يا غوث الأعظم إذا أردت أن تنظر إليّ في محل فاختر قلباً فارغاً عن سوائي."39

ومن ثمرات النفس الكاملة التي تتعدد ألواها، مروراً بالمقامات الستة التي تسبقها حتى تنضج مذاقاً وشكلاً: اليقين، والرحمة، والزهد، والسلامة. وطبيعة العائد النفسي لهذه الثمرات الأربع تكمن في "النناغم الكلى" مع الوجود الذي يجرى على حكم مشيئة الواجد.

بيد أن التناغم الكلي لا يوحي، قط، بالتواكل المقيت، ولا بسقوط الأسباب، ولا بالتقاعس عن مقاومة الشر، إذ أن جزءاً من فاعلية التناغم المقصود يظل معلقاً بما هو نقيض ذلك: عمل الجوارح، ورؤية الأسباب، والغضب لأمر الله وهيه. ولكن كل هذا يظل مقترناً بإيمان لا يتزعزع بمبدأين: الأول أن ما كان

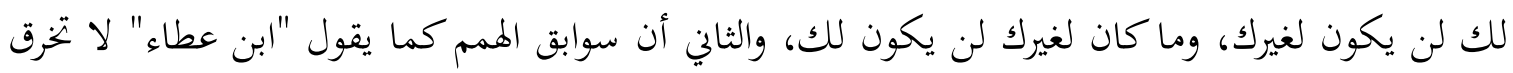
أسوار الأقدار.

فإذا عدنا مرة أخرى، إلى الثمرات الأربع من ثمرات النفس الكاملة لنرى تجليات حقلها النفسي في واقع الحياة الزمنية من خلال تعاقبات شئونه صيرورة "وثباتاً" (تكراراً)، وبتربة "ومعنى" وسعنا أن نقول إن اليقين دواء النفس من الشك، وهو المعراج جها إلى مستقر الراحة، وأن الرحمة دواء النفس من غواية التجبر أو التملك، وهي تخريرها من شهوة البطش بلذة العفو والحنوّ، وأن الزهد دواء النفس من الحقد والطمع والغيرة، وهو كبح جماحها عن السقوط في هاوية السخط والنقمة، وأن السلام دواء النفس من نزوع التنافس والمشاحنة، وهو ردُّها إلى براءة حساسيتها الغفل قبل أن تفسد بانطاط العالم الواقعي. الشك وشهوة البطش، والحقد والطمع والغيرة والتنافس والمشاحنة، داءات تنتك بالنفس الإنسانية في مستواها التجريبي الزمني المحسوس، وتزرع فيها الشقاء والألم بدلاً عن السعادة الروحية الأبدية. لذلك تلح الممارسة الصوفية على استئصال شأفة هذه الداءات المعضلة، بطرائق مختلفة سعياً إلى الفوز بـ "التناغم الكلي" الأخير الذي يقول عنه أحد العارفين الكبار: نحن في لذة لو عرفها الملوك لقاتلونا عليها بالسيوف ولعل هذه اللذة هي لذة

39 
المشاهدة. وهي لذة يرفد بها نور المشهود حياة نفس العبد الذي لا يدرك مشهوده بالأبصار، بل بخفايا كيانه المفتوح على عوالم التجلي، وبلطائف البصيرة المنعكسة على كل جارحة من جوارحه، وخلية من خلاياه.

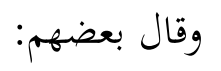

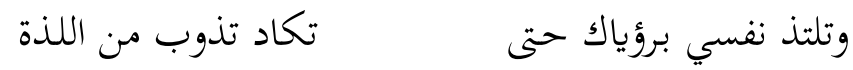

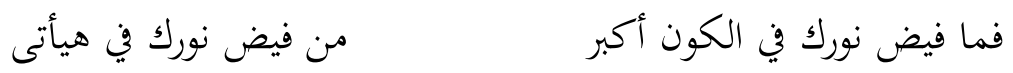

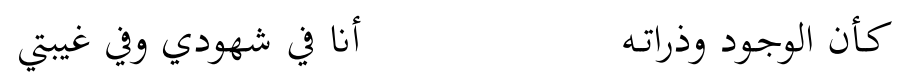

وربما لا تنفصل هذه اللذة في الحضور المتسامي للأنا الصوفية، عن سجية نبذ العالم الواقعي السقيم ذاته بما فيه من مظاهر العمى والنقصان والخسارة، قال الشاذلي رمهه الله: لأن يغنيك الله عن الدنيا خير من أن يغنيك بها، فوالله ما استغنى هها أحد، وقال له شخص: عندك الكيمياء فعلمني.. فقال: ما أراك لذلك قابلاً، فقال: أي والله أقبل، فقال: أسقط الخلق من قبلك، واقطع الطمع من ربك أن يعطيك غير ما سبق لك. قال: لا أطيق هذا. فقال: ألم أقل لك أنك لا تقبل، انصرف. 40

وقيل: حقيقة العافية بقاء العبد مع الله، وحقيقة الأنس نور لا ظلمة فيه، وحصين لا ثلاثة فيه،

$$
\text { وحقيقة المشاهدة اطلاع القلوب عما أخبر الله عن الغيوب. } 41
$$

والحضور المتسامي للأنا الصوفية يستمد صفاته النفسية من حقائق أهمها العافية، والأنس، والمشاهدة. وبهذا تتحقق ديمومته، وينقطع زواله، فعين القرب من الحق ذاتا عين النجاة من الرق، على المسافة التي تقع بين الهو والأغيار، وهذه المسافة إذا اتصفت بظاهرها ظلت على ظلمتها، وإذا اتصفت بباطنها وسمتها معية التحلي فصارت حضرة للأنوار والأسرار.

$$
\begin{aligned}
& 40 \\
& 41 \text { الخالدي، أحمد النقشبدي. الأولياء وأوصافهم، ت: أديب نصر الدين، بيروت: دار الانتشار العربي، } 1997 \text { م، ص } 113
\end{aligned}
$$


ومن دقائق النفس الكاملة كوغا تستقبل جميع واردات الحق باعتبار ما لها من علم العلم، وهو الجهل عن العلم بحسب اصطلاح الصوفية. وهذا المقام يتلو كل علم تم تحصيله. ويكون كذلك لأن عتبة المعنى التي تخص كنه الذات الإلهية عتبة تتصل ببطون البطون أي تتصل بعجز الفهوم عن إدراك ماهية الكنه.

وهنا تكاد النفس الكاملة أن تسبح فيما وراء منتهى معراجها ذاته، ولكن الله يحفظ لها البقاء بعد الفناء حتى تظل قائمة بروح حياته وحده على ما هي عليه في عالم النشأة الأولى.

وثمرة النفس الكاملة، عند هذه الذروة الكبرى هي (الوحدة) والوحدة غير الاتحاد، إذ تقوم على الانعكاس في الماهية لا على حلول الماهية في الماهية كما يصور الوهم للواهم

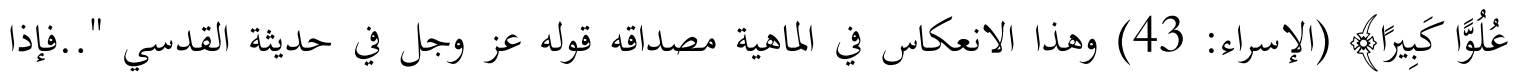
أحببته كنت سمعه، وبصره، ويده" وقوله صلى الله عليه وسلم: "إنما ينظر المؤمن بنور الله الذي خلق منه" (رواه الديلمي عن ابن عباس مرفوعاً) وقال عبد الكريم الجيلي رمهه الله: ليس حقيقة النفس إلا الروح، وليس حقيقة الروح إلا الحق.. فكل ما تفعله النفس من الخير هو بالإلهام الإلهي، وكل ما تفعله من الشر هو بالاقتضاء الطبيعي.. ثم إذا انقطعت الخواطر المذمومة مطلقاً تسمى مطمئنة...ثم إذا انقطعت الخواطر المحمودة كما انقطعت المذمومة، واتصفت بالأوصاف الإلهية، وتحققت بالحقائق الذاتية، فاسم العارف اسم معروف، وصفاته صفاته، وذاته ذاته. 42 فأحادية الاسم والصفة والذات، هنا، أحادية وحدة لا اتحاد، ومناط هذه الأحادية الانعكاس لا الحلول.

وسعادة النفس القصوى، إذن، في انعكاس ماهية الحق الخالق على ماهية الحق المخلوق باعتبار الصورة المحمدية وتسلسلها معنى وحقيقة، في قوالب الوارثين لها، ومن هنا تفسير بعضهم لقوله صلى الله عليه وسلم: "المؤمن مرآة المؤمن" فالمؤمن اسم مشترك بين الله والعبد. والعبد مرآة الله في أصل استعداده وقابليته للكمال الذي يتجلى به سبحانه من حيث جلال الجمال على الوجود كله.

هكذا تتكشف سيكولوجية التصوف بوصفها سيكولوجية الحضور المتسامي بين الدافع والغاية. وهنا يلوح لي أن التصوف هو الالتفاف النفسي حول المخلوقية من أجل الإشراف على الخالقية في امتدادها من

$$
\text { 42 }
$$


الأزل إلى الأبد، وهو امتداد يعلو على التاريخ والزمن وعرضية الحياة البشرية، ويضعنا في قلب معنى قوله

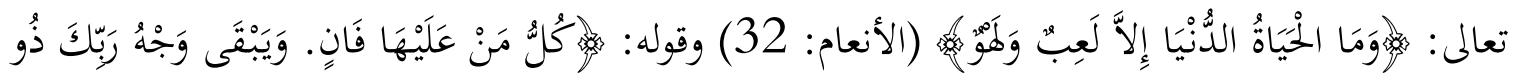

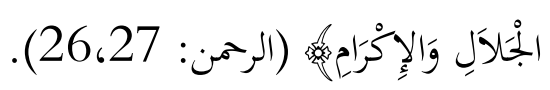

خاتمة:

تقودنا الدراسة الاستشافية للظاهرة الصوفية إلى كون التصوف يمثلُ في مفاهيمه العميقة وطرق ممارسته، قواماً متماسكاً لما يمكن أن نسميه "بعلم النفس الديني." وهو علم ينهض على مبادئ نظرية محددة، وينطلق منها إلى فرعين عمليين هما: الآليات العلاجية لأمراض النفس، وآليات التسامي أو العلو فيما يخص النزوع الماورائي بالمادة الإنسانية. ومدار الآليات العلاجية كلها قائم على التوجيه الذاتي وتعدد وسائله من

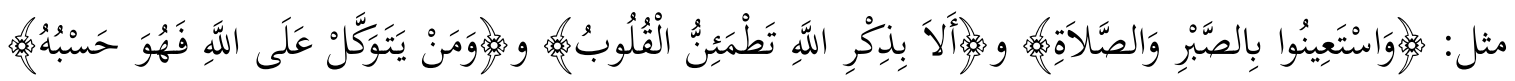
وغيرها من وسائل التثبيت والتعضيض، أما مدار الآليات الخاصة بالعلو فقائم على الاستبطان والغوص الداخلي، والاعتماد في ذلك على كشف الباطن من وراء الظاهر كقول الجنيد رممه الله: "الشكر أن لا تعصى الله بنعمه"، وقول بن عطاء الله السكندري: "الزهد زهدان: جلي وخفي، فالجلي الزهد في فضول الحلال من مأكول وملبوس، والخفي الزهد في التدبير مع الله تعالى". 43 ويتناول علم النفس الديني من منظوره الخاص، جميع الظواهر الإنسانية التي تتناولها علوم النفس الأخرى: علم النفس التحليلي، علم النفس ريس السلوكي، علم النفس الاجتماعي، علم النفس الوجودي.. الخُ. ولكنه يقوم بالتشديد على بعض الظواهر وإبرازها أكثر من غيرها بوصفها ظواهر محورية ومهيمنة مثل: إشكال الانفعال، الرموز، الاغتراب، المستوى فوق الحسي للاستجابة، الاستدماج، المفارقة الشعورية، الحدس، الإيحاء، التنامي الوجداني.. الخ، ويجاوز علم النفس الديني في جانب من جوانبه حدود الموضوع النفسي ذاته إلى بعض الوقائع الباراسيكولوجية كالروح

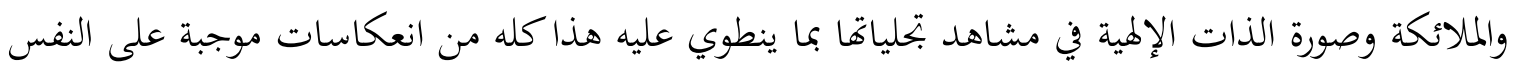
التي تنشد حق اليقين، حيث حق اليقين نعت العيان، وعين اليقين حكم البيان، وعلم اليقين شرط البرهان بتعبير القشيري، ومن الناحية العملية البحت تفيد الاستعانة بالعديد من مبادئ التصوف وسلوكياته في

$$
\text { 43 }
$$


تعديل شيئين: أولما المسار الحضاري المفرط في المادية وشهوة الصراع والتدمير والتملك على المستوى الإنساني العام، وثانيهما النزوع الحسي والاستهلاكي المتفاقم لدى الإنسان المعاصر على المستوى الفردي الخاص. كذلك يبدو تكريس بعض القناعات الصوفية المهمة كالغبة والتوكل واليقين، والرضا علاجاً ناجحاً لكثير من الإمراض والمشكلات النفسية التي تعترى الفرد المعاصر كاليأس والإحباط والقلق والخوف والاكتئاب والسادية وغيرها.

وينغي أن تقوم مواصلة البحث في هذا الموضوع المثير على هدف منهجي واضح هو تأسيس نسق منتظم، وكامل الأبعاد، ومتفرد المحتوى، لما يسمى بـ "علم النفس الديني" وما يشتق عنه من فروع نحن في أمس الحاجة إليها: علم نفس الأخلاق، علم نفس التربية، علم نفس الفكر، علم النفس الحضاري.. الخ. وهذه الفروع التي أُسس لها من منظورات مختلفة تحتاج إلى تأسيس جديد من منظور أخر هو منظور العرفانية الإسلامية. ومن شأن هذه العرفانية أن يكون لما إطارها الخاص ومنهجها الخاص وغايتها الخاصة وحينئذ لن تسهم هذه العرفانية في انتشال المجتمع المسلم فقط من بعض أزماته الطاحنة، بل ستسهم، أيضاً، في انتشال المجتمع الإنساتي كله من عثرات خلقها بنفسه لنفسه نتيجة لسعيه الدؤوب نهو الازدهار المادي والتكنولوجي دون نواظم لهذا السعي، ونتيجة لسوء فهمه لما تعنيه "السعادة" من مكونات متكاملة، ونتيجة لإصراره على ترسيخ مفهوم للحرية خال من الشروط وضمانات العدالة. 